\title{
Lifestyle in pregnancy and cryptorchidism in sons: a study within two large Danish birth cohorts
}

This article was published in the following Dove Press journal:

Clinical Epidemiology

\author{
Camilla Kjersgaard' \\ Linn Håkonsen Arendt ${ }^{1,2}$ \\ Andreas Ernst' \\ Morten Søndergaard \\ Lindhard ${ }^{2}$ \\ Jørn Olsen ${ }^{1,3}$ \\ Tine Brink Henriksen ${ }^{2}$ \\ Katrine Strandberg-Larsen ${ }^{4}$ \\ Cecilia Høst \\ Ramlau-Hansen' \\ 'Department of Public Health, Section \\ for Epidemiology, Aarhus University, \\ Aarhus, ${ }^{2}$ Perinatal Epidemiology \\ Research Unit, Department of \\ Pediatrics, Aarhus University Hospital, \\ Aarhus, ${ }^{3}$ Department of Clinical \\ Epidemiology, Aarhus University \\ Hospital, Aarhus, ${ }^{4}$ Department of \\ Public Health, Section of Social \\ Medicine, Copenhagen University, \\ Copenhagen, Denmark
}

Correspondence: Camilla Kjersgaard Department of Public Health, Section for Epidemiology, Aarhus University, Bartholins Allé 2, 8000 Aarhus C,

Denmark

Tel +45 40194438

Email ck@ph.au.dk
Purpose: Cryptorchidism is the most frequent congenital malformation in boys and is associated with low sperm count, infertility and testicular cancer. Unhealthy maternal lifestyle during pregnancy such as smoking, high prepregnancy body mass index (BMI) as well as alcohol and caffeine intake may constitute possible risk factors for cryptorchidism, but results from the few previous studies are conflicting. We aimed to explore the association between maternal lifestyle factors and occurrence of cryptorchidism in sons.

Patients and methods: The Danish National Birth Cohort and the Aarhus Birth Cohort provided information on maternal lifestyle from early pregnancy. Data were linked to several Danish health registers, multiple imputation was used to handle missing data and Cox proportional hazards models were used to adjust for potential confounders.

Results: In total, 85,923 boys were included, and of them, $2.2 \%$ were diagnosed with cryptorchidism. We observed the strongest associations between maternal tobacco smoking and prepregnancy BMI and cryptorchidism. Sons of women who smoked 10-14 cigarettes/day had the highest hazard ratio (HR) for cryptorchidism (1.37; 95\% CI: 1.06-1.76), and for maternal $\mathrm{BMI} \geq 30 \mathrm{~kg} / \mathrm{m}^{2}$, the HR was 1.32 (95\% CI: 1.06-1.65). Binge drinking was associated with an $\mathrm{HR}<1$, if the women had one or two episodes in pregnancy (HR: 0.81; 95\% CI: 0.67-0.98). Average maternal alcohol intake and caffeine intake during pregnancy were not significantly associated with a higher occurrence of cryptorchidism detected at birth or later in life.

Conclusion: Maternal tobacco smoking, overweight and obesity in pregnancy were associated with higher occurrence of cryptorchidism in boys in this study.

Keywords: alcohol, smoking, overweight, obesity, caffeine

\section{Introduction}

Cryptorchidism (undescended testis at birth) is the most common male congenital anomaly registered at birth or later. ${ }^{1}$ The condition has been associated with an increased risk of low semen quality, infertility and testicular cancer in adulthood despite routinely corrective surgery during childhood. ${ }^{2}$ Low birth weight and prematurity are well-documented predictors of cryptorchidism, ${ }^{3}$ but in most cases, the cause is unidentified. Studies have indicated that the intrauterine environment and maternal factors probably have greater influence on the risk of cryptorchidism than paternal factors or genetics. ${ }^{4}$ The multistage descent of the testes starts in early pregnancy around gestational week 8 and continues until approximately week 35 of gestation; ${ }^{5}$ thus, maternal lifestyle and environmental exposures may interfere with normal testicular descent throughout pregnancy. ${ }^{2}$ 
Several maternal lifestyle factors have been investigated in relation to cryptorchidism such as tobacco smoking, alcohol drinking, obesity and intake of caffeinated beverages during pregnancy. ${ }^{6-35}$ However, most studies have been small, and results are inconsistent.

Using two large population-based cohorts, we aimed to model the association between risk of cryptorchidism and the aforementioned lifestyle factors. We hypothesized that exposure to maternal tobacco smoking, prepregnancy overweight and obesity as well as maternal intake of alcohol and caffeine would lead to a higher prevalence of cryptorchidism.

\section{Patients and methods \\ Study population}

The study utilized data from the Danish National Birth Cohort (DNBC) and the Aarhus Birth Cohort (ABC). The DNBC is a nationwide birth cohort that enrolled pregnant women from 1996 to 2002. All pregnant Danish-speaking women in Denmark who wanted to carry their pregnancy to term were eligible. Approximately $60 \%$ of the invited women participated and took part in four computer-assisted telephone interviews, two of them conducted during pregnancy: the earliest around gestational week 12, and then again at approximately gestational week $30 .{ }^{36,37}$

The ABC is an ongoing pregnancy cohort established in 1989. All pregnant women attending routine antennal care at Aarhus University Hospital, Denmark, have since 1989 been invited to participate by completing a self-administered questionnaire around the time of late first or early second trimester on lifestyle during pregnancy as well as on the medical and obstetric history. Until now, $\sim 80 \%$ of the invited women have participated. ${ }^{38,39}$

For this study, we included women enrolled in the two birth cohorts, who gave birth to a live-born singleton boy from 1989 to 2012 . Women were eligible if they had completed one of the prenatal interviews (DNBC) or questionnaires $(\mathrm{ABC})$ and had a valid unique civil registration number. Since 1968, the Danish Civil Registration System has been assigning a unique civil registration number to all residents, ${ }^{40}$ which is used in the health care system in Denmark. This unique identifier was used to link the data from the birth cohorts with the following national health registries: the Danish Medical Birth Register, with information regarding the pregnancy; ${ }^{41}$ the Danish National Patient Register, with information on all diagnosis- and surgical codes for all in- and outpatient hospital contacts, ${ }^{42}$ and the
Danish Integrated Database for Labour Market Research, with information on social data. ${ }^{43}$

\section{Exposure assessment}

The exposures used in this study were the following maternal lifestyle factors; tobacco smoking, average alcohol intake and binge drinking, prepregnancy body mass index (BMI) as well as intake of caffeine from coffee, tea and cola beverages.

In the DNBC, this information was available from the telephone interviews. We used the first interview around gestational week 12 as the main source of exposure information. This was chosen to obtain a shorter recall period. If this information was missing, we used the information from the telephone interview around week 30.

In the $\mathrm{ABC}$, information on maternal lifestyle came from the self-administered questionnaires. In the early period of the ABC (1989-1999), some women completed a second questionnaire in early third trimester, and if information was missing from the first questionnaire in early pregnancy, we used the information from the second. For those women who were included in both DNBC and $\mathrm{ABC}(\mathrm{n}=3,479)$, we used the information from the DNBC. If data on either maternal tobacco smoking or maternal height or weight were missing from both birth cohorts, we used information from the Danish Medical Birth Register on maternal tobacco smoking ( $\mathrm{n}$ $=230$, available from 1996 to 2012) and maternal weight and height ( $\mathrm{n}=58$ and $\mathrm{n}=106$, available from 2004 to 2012).

\section{Maternal tobacco smoking}

Maternal tobacco smoking during pregnancy was categorized as follows: non-smoking, stopped smoking in first trimester and 1-9, 10-14 or $\geq 15$ cigarettes/day. Because of a higher nicotine content in other tobacco products than in cigarettes, we multiplied the numbers of cigars, cheroots and pipes by 4. "Stopped smoking" were women who reported to have smoked at the first detection of pregnancy or in very early pregnancy and did not smoke when they were interviewed (DNBC) or completed the questionnaires $(\mathrm{ABC})$.

\section{Maternal weekly alcohol intake}

Maternal weekly alcohol intake during pregnancy was based on the combined average weekly intake of alcoholic beverages. One alcoholic drink was defined as one glass of wine, one bottle of beer $(0.33 \mathrm{~L})$ or one glass of liqueur $(12.5 \mathrm{~g}$ alcohol/unit). The total weekly intake was categorized into $0-<1,1-2,3-4$ and $\geq 5$ drinks. 


\section{Maternal binge drinking}

Maternal binge drinking was categorized according to the frequency of drinking five or more alcoholic drinks in one occasion, i.e., binge drinking episodes since the onset of pregnancy. We categorized the number of binge drinking episodes during pregnancy as $0,1,2$ and $\geq 3$ times. In $\mathrm{ABC}$, questions on maternal binge drinking were not included in the early part of the cohort (1989-1998), so we limited our analysis on binge drinking in $\mathrm{ABC}$ to 1998 and onward.

\section{Maternal prepregnancy BMI}

Maternal prepregnancy BMI $\left(\mathrm{kg} / \mathrm{m}^{2}\right)$ was calculated and categorized according to the World Health Organization classification: underweight: $<18.5 \mathrm{~kg} / \mathrm{m}^{2}$, normal weight: $18.5-24.9 \mathrm{~kg} / \mathrm{m}^{2}$, overweight: $25-29.9 \mathrm{~kg} / \mathrm{m}^{2}$ and obese: $\geq 30 \mathrm{~kg} / \mathrm{m}^{2}{ }^{44}$ Outliers with excessively high or low values were recoded to missing.

\section{Maternal caffeine intake}

Maternal caffeine intake during pregnancy was based on caffeine intake from coffee, tea and cola and was categorized into $0,1-300,301-600$ and $\geq 600 \mathrm{mg}$ caffeine/day. We defined one cup of coffee as $100 \mathrm{mg}$ of caffeine, one cup of tea as $50 \mathrm{mg}$ of caffeine and $1 / 2 \mathrm{~L}$ of cola as $50 \mathrm{mg}$ of caffeine according to published literature..$^{45,46}$

\section{Covariates}

Information on covariates were either self-reported or retrieved from the Danish health registers ${ }^{41}$ A priori, potential mediators and confounders for the five different exposures were identified by the existing literature and the use of directed acyclic graphs (DAGs). ${ }^{47}$ In all models, we adjusted for years of education ( $\leq 9,10-14$ and $\geq 15$ years), maternal age at birth $(<25,25-29,30-34$ and $\geq 35$ years), parity (nulliparous and multiparous women), birth cohort (ABC or DNBC) and calendar year at birth (1989-1993, 1994-1998, 1999-2003, 2004-2008 and 2009-2012), the latter to account for the trend in the prevalence of diagnosed male genital anomalies in the Danish National Patient Register, the difference in follow-up time and the change in registration from International Classification of Diseases (ICD) version 8 to version 10 during the study period. The analyses for maternal tobacco smoking, maternal caffeine intake and maternal weekly alcohol intake and binge drinking were further adjusted for time to pregnancy (unplanned pregnancies, $0-5$ months, $6-12$ months and $\geq 12$ months without assisted reproductive technology (ART) and $\geq 12$ months with ART). The five exposures were mutually adjusted.

\section{Outcome measures}

We studied two outcomes. The first was boys with a cryptorchidism diagnosis, defined as a diagnosis of cryptorchidism according to ICD-8 (1977-1993): 75210, 75211, 75219 and ICD-10 (1994-2012): Q53. Second, we used a definition with higher positive predictive value ${ }^{48}$ and classified boys as having cryptorchidism if they had both a diagnosis of cryptorchidism and underwent corrective surgery for cryptorchidism (orchiopexy). The Nordic classification of surgical procedures codes: KKFH00, KKFH01, KKFH10 or surgery and treatment classification of the Danish National Board of Health codes: 55640, 55600 was used to define orchiopexy.

\section{Missing information}

Missing data ranged from none for, e.g., maternal age, calendar year of birth and birth cohort, to $11.6 \%$ for maternal binge drinking (Table 1). Ignoring maternal binge drinking, $84 \%$ of the study population had complete information on all exposures, covariates and the outcomes.

We accounted for missing data by using multiple imputation. ${ }^{49}$ This is a method widely recommended if data are missing at random (MAR); ${ }^{49}$ data is considered to be almost MAR if the systematic difference between observed and missing values can be "explained" by the observed data, an assumption we assumed.$^{50}$ Current guidelines recommend that the number of imputations should be at least equal to the percentage of incomplete cases. ${ }^{51}$ We fitted a multiple imputation model using chained equations and imputed 50 datasets with the following variables included in the model: maternal tobacco smoking (continuous), maternal weekly alcohol intake (categorical), maternal binge drinking (continuous), maternal prepregnancy weight and height (continuous), maternal caffeine intake (continuous), cryptorchidism, hypospadias, other malformations, maternal years of education (categorical), maternal age at birth (continuous), time to pregnancy (categorical), ART (binary), parity (categorical), nausea (binary), calendar year at birth (continuous), birth weight (continuous), gestational age (continuous) and type of cohort. Continuous variables were interval censored to ensure biologically plausible values. Binary variables were modeled using the logit function and continuous variables using the linear regression. Maternal prepregnancy weight was right skewed and transformed to approximate normality by a shifted logarithm transformation. ${ }^{51}$ 
Table I Distribution of maternal characteristics according to cryptorchidism among 85,923 singleton live-born boys, Denmark, I989-2012

\begin{tabular}{|c|c|c|c|c|c|c|c|c|c|}
\hline \multirow[t]{3}{*}{ Characteristic } & \multirow{3}{*}{$\begin{array}{l}\text { Distribution of } \\
\text { participants, \% }\end{array}$} & \multicolumn{4}{|c|}{ Cryptorchidism } & \multicolumn{4}{|c|}{ Cryptorchidism - corrective surgery } \\
\hline & & \multicolumn{2}{|l|}{$\overline{\text { Yes }}$} & \multicolumn{2}{|l|}{ No } & \multicolumn{2}{|l|}{$\overline{\text { Yes }}$} & \multicolumn{2}{|l|}{ No } \\
\hline & & $\mathbf{n}$ & $\%$ & $\mathbf{n}$ & $\%$ & $\mathbf{n}$ & $\%$ & $\mathbf{n}$ & $\%$ \\
\hline Total & & $\mathrm{I}, 864$ & 2.2 & 84,059 & 97.8 & 1,098 & 1.3 & 84,825 & 98.7 \\
\hline \multicolumn{10}{|c|}{ Smoking (cigarettes/day) } \\
\hline Nonsmoker & 73.8 & 1,289 & 2.0 & 62,117 & 98.0 & 752 & 1.2 & 62,654 & 98.8 \\
\hline Stopped smokers & 9.7 & 211 & 2.5 & 8,118 & 97.5 & 120 & 1.4 & 8,209 & 98.6 \\
\hline $1-9$ & 8.6 & 180 & 2.4 & 7,229 & 97.6 & 112 & 1.5 & 7,297 & 98.5 \\
\hline $10-14$ & 4.7 & 110 & 2.7 & 3,946 & 97.3 & 74 & 1.8 & 3,982 & 98.2 \\
\hline$\geq 15$ & 2.9 & 66 & 2.6 & 2,450 & 97.4 & 37 & 1.5 & 2,479 & 98.5 \\
\hline Missing & 0.2 & & & & & & & & \\
\hline \multicolumn{10}{|c|}{ Alcohol (drinks/week) } \\
\hline None to $<1$ & 70.8 & $\mathrm{I}, 34 \mathrm{I}$ & 2.2 & 59,456 & 97.8 & 792 & 1.3 & 60,005 & 98.7 \\
\hline $\mathrm{I}-2$ & 19.7 & 351 & 2.2 & 16,539 & 97.9 & 197 & 1.2 & 16,693 & 98.7 \\
\hline $3-4$ & 3.9 & 71 & 2.1 & 3,314 & 97.9 & 44 & 1.3 & $3,34 I$ & 98.7 \\
\hline$\geq 5$ & 1.6 & 20 & 1.4 & $\mathrm{I}, 378$ & 98.6 & 15 & 1.1 & $\mathrm{I}, 383$ & 98.9 \\
\hline Missing & 4.0 & & & & & & & & \\
\hline \multicolumn{10}{|c|}{ Binge drinking episodes (times) } \\
\hline 0 & 61.6 & 991 & 2.3 & 41,658 & 97.7 & 592 & 1.4 & 42,057 & 98.6 \\
\hline I & 16.6 & 208 & 1.8 & 11,298 & 98.2 & 125 & 1.1 & $|1,38|$ & 98.9 \\
\hline 2 & 6.3 & 78 & 1.8 & 4,299 & 98.2 & 44 & 1.0 & 4,333 & 99.0 \\
\hline$\geq 3$ & 3.9 & 59 & 2.2 & 2,646 & 97.8 & 39 & 1.4 & 2,666 & 98.6 \\
\hline Missing & 11.6 & & & & & & & & \\
\hline \multicolumn{10}{|c|}{ Prepregnancy BMI (kg/m²) } \\
\hline$<18.5$ & 4.9 & 95 & 2.3 & 4,097 & 97.7 & 53 & 1.3 & 4,139 & 98.7 \\
\hline $18.5-24.9$ & 67.3 & $\mathrm{I}, 145$ & 2.0 & 56,672 & 98.0 & 696 & 1.2 & 57,121 & 98.8 \\
\hline $25-29.9$ & 16.8 & 378 & 2.6 & 14,073 & 97.4 & 205 & 1.4 & 14,246 & 98.6 \\
\hline$\geq 30$ & 6.8 & 149 & 2.6 & 5,699 & 97.5 & 93 & 1.6 & 5,755 & 98.4 \\
\hline Missing & 4.2 & & & & & & & & \\
\hline \multicolumn{10}{|c|}{ Caffeine (mg/day) } \\
\hline 0 & 9.4 & 149 & 1.9 & 7,925 & 98.2 & 89 & I.I & 7,985 & 98.9 \\
\hline $1-300$ & 64.4 & $|| 6 \mid$, & 2.1 & 54,198 & 97.9 & 697 & 1.3 & 54,662 & 98.7 \\
\hline $30 I-600$ & 14.3 & 293 & 2.4 & 12,032 & 97.6 & 169 & $\mathrm{I} .4$ & 12,156 & 98.6 \\
\hline$>600$ & 5.5 & 116 & 2.5 & 4,587 & 97.5 & 68 & 1.5 & 4,635 & 98.6 \\
\hline Missing & 6.4 & & & & & & & & \\
\hline \multicolumn{10}{|c|}{ Age at delivery (years) } \\
\hline$<25$ & 10.8 & 247 & 2.7 & 9,031 & 97.3 & 145 & 1.6 & 9,133 & 98.4 \\
\hline $25-29$ & 37.5 & 672 & 2.1 & 31,524 & 97.9 & 405 & 1.3 & $31,79 \mid$ & 98.7 \\
\hline $30-34$ & 36.3 & 659 & 2.1 & 30,544 & 97.9 & 387 & 1.2 & 30,816 & 98.8 \\
\hline$>35$ & 15.4 & 286 & 2.2 & 12,960 & 97.8 & 161 & 1.2 & 13,085 & 98.8 \\
\hline Missing & 0 & & & & & & & & \\
\hline \multicolumn{10}{|c|}{ Parity (before this birth) } \\
\hline 0 & 48.3 & 979 & 2.4 & 40,492 & 97.6 & 583 & 1.4 & 40,888 & 98.6 \\
\hline$\geq 1$ & 51.6 & 885 & 2.0 & 43,498 & 98.0 & 515 & 1.2 & 43,868 & 98.8 \\
\hline Missing & 0.1 & & & & & & & & \\
\hline \multicolumn{10}{|c|}{ Education (years) } \\
\hline Short $\leq 9$ & 10.1 & 225 & 2.6 & 8,438 & 97.4 & 122 & 1.4 & 8,541 & 98.6 \\
\hline Medium 10-14 & 42.1 & 806 & 2.2 & 35,323 & 97.8 & 485 & 1.3 & 35,644 & 98.7 \\
\hline Long $\geq 15$ & 47.2 & 826 & 2.0 & 39,698 & 98.0 & 488 & 1.2 & 40,036 & 98.8 \\
\hline Missing & 0.7 & & & & & & & & \\
\hline Time to pregnar & nths) & & & & & & & & \\
\hline $0-5$ & 50.4 & 889 & 2.1 & 42,424 & 98.0 & 525 & 1.2 & 42,788 & 98.8 \\
\hline $6-12$ & 12.7 & 240 & 2.2 & 10,695 & 97.8 & 142 & 1.3 & 10,793 & 98.7 \\
\hline$\geq 12$ without $A R T$ & 5.7 & 121 & 2.5 & 4,796 & 97.5 & 72 & 1.5 & 4,845 & 98.5 \\
\hline$\geq 12$ with $A R T$ & 5.3 & 108 & 2.4 & 4,453 & 97.6 & 68 & 1.5 & 4,493 & 98.5 \\
\hline Unplanned & 19.2 & 370 & 2.2 & 16,124 & 97.8 & 226 & 1.4 & 16,268 & 98.6 \\
\hline Missing & 6.6 & & & & & & & & \\
\hline
\end{tabular}


Table I (Continued)

\begin{tabular}{|c|c|c|c|c|c|c|c|c|c|}
\hline \multirow[t]{3}{*}{ Characteristic } & \multirow{3}{*}{$\begin{array}{l}\text { Distribution of } \\
\text { participants, \% }\end{array}$} & \multicolumn{4}{|c|}{ Cryptorchidism } & \multicolumn{4}{|c|}{ Cryptorchidism - corrective surgery } \\
\hline & & \multicolumn{2}{|l|}{ Yes } & \multicolumn{2}{|l|}{ No } & \multicolumn{2}{|l|}{ Yes } & \multicolumn{2}{|l|}{ No } \\
\hline & & $\mathbf{n}$ & $\%$ & $\mathbf{n}$ & $\%$ & $\mathbf{n}$ & $\%$ & $\mathbf{n}$ & $\%$ \\
\hline \multicolumn{10}{|l|}{ Cohort } \\
\hline DNBC & 53.7 & 1,076 & 2.3 & 45,089 & 97.7 & 627 & 1.4 & 45,538 & 98.6 \\
\hline $\mathrm{ABC}$ & 46.3 & 788 & 2.0 & 38,970 & 98.0 & 471 & 1.2 & 39,287 & 98.8 \\
\hline Missing & 0 & & & & & & & & \\
\hline \multicolumn{10}{|c|}{ Calendar year of birth } \\
\hline 1989-1993 & 7.7 & 218 & 2.8 & 7,523 & 97.2 & 129 & $\mathrm{I} .7$ & 7,612 & 98.3 \\
\hline $1994-1998$ & 17.3 & 368 & 2.5 & 14,525 & 97.5 & 192 & 1.3 & $|4,70|$ & 98.7 \\
\hline 1999-2003 & 55.4 & 1,080 & 2.3 & 46,482 & 97.7 & 640 & 1.4 & 46,922 & 98.7 \\
\hline 2004-2008 & 10.8 & 155 & 1.7 & 9,125 & 98.3 & 106 & I.I & 9,174 & 98.9 \\
\hline $2009-2012$ & 7.5 & 43 & 0.7 & 6,404 & 99.3 & 31 & 0.5 & 6,416 & 99.5 \\
\hline Missing & 0 & & & & & & & & \\
\hline
\end{tabular}

Abbreviations: BMI, body mass index; ART, assisted reproductive technology; DNBC, Danish National Birth Cohort; ABC, Aarhus Birth Cohort.

\section{Data analyses}

Cryptorchidism is by definition present at birth but may not be diagnosed at birth; the condition may thus be diagnosed at any time during childhood., 32 By the end of follow-up (December 31, 2012), not all boys in the DNBC and the ABC were of the same age. To account for this variation in followup time, we used a Cox proportional hazards model, with the boy's age as the underlying time axis. The boys entered the risk set at birth and were followed until their age at diagnosis of cryptorchidism, death, emigration from Denmark, or the end of follow-up, whichever came first. Crude and adjusted hazard ratios (HRs) with 95\% CI for cryptorchidism according to the different maternal lifestyle factors were estimated. Since the cohorts included siblings, the CIs were calculated using robust standard errors with the mother as cluster identifier. The proportional hazards assumption was verified by visual inspection of log-minus-log plots. Overall statistical significance for each exposure variable was tested using the Wald test or a test for linear trend.

We performed the following subanalyses. First, a subanalysis on the association between paternal smoking and cryptorchidism was conducted to investigate potential familial confounding. Second, we carried out a subanalysis, restricting our study population to DNBC that holds information on nausea, because women with coffee aversion and nausea are probably more likely to lower their coffee intake. Further, it has been proposed that nausea is an indicator of viability of the fetus, reflecting a healthy hormone balance in the pregnancy. ${ }^{76}$ Third, we fitted a multiple imputation model with 100 datasets and compared the results to the main analysis using 50 datasets to check the validity of our imputation model. We compared the main result with results from a complete case analysis, and finally, we performed sepa- rate analyses in the two cohorts. Data were analyzed using STATA version 11.2 at Statistics Denmark with encrypted identification numbers and no contact with individuals. The study was approved by the Danish Data Protection Agency (No. 2013-41-1964).

\section{Results}

From the DNBC, 46,165 live-born singleton boys born from 1996 to 2003 and from the ABC 39,758 live-born singleton boys born from 1989 to 2012 were included in this study. This added up to a final study population of 85,923 mother-son pairs. Of them, 1,864 (2.2\%) boys were diagnosed with cryptorchidism (1,076 from the DNBC and 788 from the ABC), and 1,098 (59\%) of them underwent corrective surgery (627 from the DNBC and 471 from the $\mathrm{ABC}$ ). The mean (range) follow-up time was 12 years (range $0-23$ years).

Table 1 lists distribution of the five exposures and relevant covariates according to cryptorchidism with and without corrective surgery. The following appeared to be more frequent among mothers of boys with cryptorchidism: tobacco smoking, overweight and obesity, caffeine intake during pregnancy, maternal age $<25$ years at birth and short education, nulliparity, time to pregnancy of $>12$ months with and without ART and giving birth between 1989 and 1993.

Table 2 presents the adjusted HRs of cryptorchidism according to the maternal lifestyle factors of interest. We observed associations between maternal tobacco smoking and maternal prepregnancy BMI and occurrence of cryptorchidism.

We observed higher HR for cryptorchidism with higher exposure to maternal tobacco smoking during pregnancy, and compared to the unexposed, boys of mothers who smoked 10-14 cigarettes/day had the highest HRs for cryptorchidism 
Table 2 HRs for cryptorchidism according to maternal smoking, weekly alcohol intake, binge drinking, prepregnancy BMI and caffeine intake during pregnancy among 85,923 singleton live-born boys, Denmark 1989-201 $2^{\text {a }}$

\begin{tabular}{|c|c|c|c|c|c|c|c|c|c|}
\hline \multirow[t]{2}{*}{ Characteristic } & \multirow{2}{*}{$\begin{array}{l}\text { Distribution of } \\
\text { participants, \% }\end{array}$} & \multicolumn{4}{|c|}{ Cryptorchidism } & \multicolumn{4}{|c|}{ Cryptorchidism - surgery } \\
\hline & & $\begin{array}{l}\text { Cases, } \\
\% \\
\end{array}$ & $\begin{array}{l}\text { Crude } \\
\text { HR } \\
\end{array}$ & aHR & $95 \% \mathrm{Cl}$ & $\begin{array}{l}\text { Cases, } \\
\% \\
\end{array}$ & $\begin{array}{l}\text { Crude } \\
\text { HR } \\
\end{array}$ & aHR & $95 \% \mathrm{Cl}$ \\
\hline \multicolumn{10}{|c|}{ Smoking (cigarettes/day) ${ }^{\mathrm{b}}$} \\
\hline Nonsmoker & 73.8 & 2.0 & 1.00 & 1.00 & Reference & 1.2 & 1.00 & 1.00 & Reference \\
\hline Stopped smokers & 9.7 & 2.5 & 1.22 & 1.19 & $(1.03-1.38)$ & 1.4 & 1.19 & 1.16 & $(0.96-1.4 I)$ \\
\hline $1-9$ & 8.9 & 2.5 & 1.12 & 1.07 & $(0.91-1.25)$ & 1.5 & 1.17 & 1.15 & $(0.93-1.4 I)$ \\
\hline $10-14$ & 4.7 & 2.7 & 1.21 & 1.13 & $(0.92-1.39)$ & 1.8 & 1.40 & 1.37 & $(1.06-1.76)$ \\
\hline$\geq 15$ & 2.9 & 2.6 & 1.18 & 1.09 & $(0.84-1.42)$ & 1.5 & 1.13 & 1.11 & $(0.78-1.57)$ \\
\hline Test for trend & & & & 1.01 & $(1.00-1.02)$ & & & 1.02 & $(1.00-1.03)$ \\
\hline Wald test $\mathrm{t}^{\mathrm{b}}$ & & & & & $p=0.17$ & & & & $p=0.10$ \\
\hline \multicolumn{10}{|c|}{ Alcohol (drinks/week) ${ }^{c}$} \\
\hline None to $<1$ & 74.1 & 2.2 & 1.00 & 1.00 & Reference & 1.3 & 1.00 & 1.00 & Reference \\
\hline $\mathrm{I}-2$ & 20.1 & 2.1 & 0.87 & 0.89 & $(0.79-1.00)$ & 1.2 & 0.83 & 0.85 & $(0.73-1.00)$ \\
\hline $3-4$ & 4.1 & 2.1 & 0.92 & 0.91 & $(0.7 \mid-1.16)$ & 1.3 & 0.96 & 0.96 & $(0.70-1.30)$ \\
\hline$\geq 5$ & 1.7 & 1.4 & 0.71 & 0.69 & $(0.44-1.08)$ & 1.1 & 0.90 & 0.87 & $(0.52-1.45)$ \\
\hline Test for trend & & & & 0.91 & $(0.84-0.99)$ & & & 0.93 & $(0.83-1.03)$ \\
\hline Wald test ${ }^{c}$ & & & & & $p=0.10$ & & & & $p=0.27$ \\
\hline \multicolumn{10}{|c|}{ Binge drinking episodes (times) ${ }^{c}$} \\
\hline None & 66.3 & 2.2 & 1.00 & 1.00 & Reference & 1.3 & 1.00 & 1.00 & Reference \\
\hline I & 21.2 & 1.7 & 0.85 & 0.83 & $(0.7 I-0.96)$ & 1.0 & 0.87 & 0.81 & $(0.67-0.98)$ \\
\hline 2 & 8.2 & 1.6 & 0.85 & 0.80 & $(0.64-1.01)$ & 1.0 & 0.82 & 0.74 & $(0.54-1.00)$ \\
\hline$\geq 3$ & 4.3 & 2.1 & 1.01 & 0.92 & $(0.7|-| .20)$ & 1.4 & I.II & 0.96 & $(0.69-1.34)$ \\
\hline Test for trend & & & & 0.94 & $(0.89-1.00)$ & & & 0.94 & $(0.87-1.02)$ \\
\hline Wald test ${ }^{c}$ & & & & & $p=0.03$ & & & & $p=0.05$ \\
\hline \multicolumn{10}{|l|}{ BMI $\left(\mathrm{kg} / \mathrm{m}^{2}\right)^{d}$} \\
\hline$<18.5$ & 5.3 & 2.3 & I.II & 1.08 & $(0.88-1.33)$ & 1.3 & 1.03 & 1.00 & $(0.76-1.32)$ \\
\hline $18.5-24.9$ & 69.9 & 2.0 & 1.00 & 1.00 & Reference & 1.2 & 1.00 & 1.00 & Reference \\
\hline $25-29.9$ & 17.9 & 2.6 & 1.31 & 1.33 & $(1.18-1.49)$ & 1.4 & 1.17 & 1.18 & $(1.01-1.38)$ \\
\hline$\geq 30$ & 7.0 & 2.6 & 1.29 & 1.29 & $(1.09-1.54)$ & 1.6 & 1.33 & 1.32 & $(1.06-1.65)$ \\
\hline Wald test ${ }^{d}$ & & & & 1.02 & $(1.01-1.03)$ & & & 1.01 & $(1.00-1.03)$ \\
\hline Test for trend & & & & & $p=0.00$ & & & & $p=0.03$ \\
\hline \multicolumn{10}{|c|}{ Caffeine (mg/day) } \\
\hline None & 9.4 & 1.9 & 0.98 & 0.97 & $(0.8 I-I .15)$ & I.I & 0.99 & 0.94 & $(0.75-1.18)$ \\
\hline $\mathrm{I}-300$ & 67.6 & 2.1 & 1.00 & 1.00 & Reference & 1.3 & 1.00 & 1.00 & Reference \\
\hline $30 I-600$ & 16.9 & 2.4 & 1.07 & 1.06 & $(0.93-1.21)$ & 1.4 & 1.02 & 1.02 & $(0.85-1.21)$ \\
\hline$>600$ & 6.1 & 2.6 & 1.09 & 1.06 & $(0.87-1.30)$ & 1.5 & 1.06 & 1.02 & $(0.79-1.33)$ \\
\hline Wald test $\mathrm{t}^{\mathrm{e}}$ & & & & 1.00 & $(1.00-1.00)$ & & & 1.00 & $(1.00-1.00)$ \\
\hline Test for trend & & & & & $p=0.77$ & & & & $p=0.96$ \\
\hline
\end{tabular}

Notes: a50 imputed sets. ${ }^{~}$ Adjusted for maternal years of education, maternal age at delivery, parity, calendar year, cohort, mothers' caffeine intake and alcohol intake, maternal prepregnancy BMl and time to index pregnancy. 'Adjusted for maternal years of education, maternal age at delivery, parity, calendar year, cohort, mothers' caffeine intake and smoking, maternal prepregnancy BMI and time to index pregnancy. 'Adjusted for maternal years of education, maternal age at delivery, parity, calendar year,

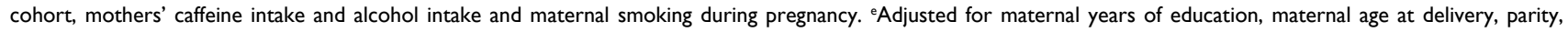
calendar year, cohort, mothers' alcohol intake and smoking, maternal prepregnancy BMI and time to index pregnancy.

Abbreviations: HR, hazard ratio; BMI, body mass index; aHR, adjusted hazard ratio.

(HR: 1.37; 95\% CI: 1.06-1.76). Sons of mothers who stopped smoking in early pregnancy also had a slightly higher HR of cryptorchidism (HR: 1.16; 95\% CI: 0.96-1.41). For maternal BMI, we observed a dose-response-like association. Sons of obese mothers (BMI: $\geq 30 \mathrm{~kg} / \mathrm{m}^{2}$ ) had the highest HR for cryptorchidism (HR: 1.32; 95\% CI: 1.06-1.65). Maternal weekly alcohol intake during pregnancy was not associated with cryptorchidism. However, one or two binge-drinking episodes during pregnancy were associated with a slightly lower HR for cryptorchidism in sons compared with no binge drinking. Finally, maternal caffeine intake during pregnancy was not associated with cryptorchidism. Results from analyses of all diagnosed boys with cryptorchidism were similar to those verified by surgery.

The subanalysis on the association between paternal smoking and cryptorchidism, showed no association (data 
not shown). Adjusting for nausea did not change the results on the association between caffeine intake during pregnancy and cryptorchidism (data not shown). Furthermore, we checked the robustness of the multiple imputation model and found similar results when imputing 100 datasets instead of 50 datasets (data not shown). The results of the complete case analyses were similar to our main results as presented (Table S1). Finally, stratifying by type of birth cohorts gave only small differences in the results. However, the association between prepregnancy obesity and risk of cryptorchidism was stronger in $\mathrm{ABC}$ compared with $\mathrm{DNBC}$, and binge drinking was only associated with decreased risk in DNBC (Table S2).

\section{Discussion}

In this large population-based study; maternal tobacco smoking during pregnancy and prepregnancy overweight and obesity were associated with a higher occurrence of cryptorchidism in sons. Our results indicated no associations between weekly alcohol consumption or caffeine intake during pregnancy and cryptorchidism at the levels consumed in these cohorts. Counterintuitively, one to two binge drinking episodes were associated with HRs $<1$ for cryptorchidism, which could be a chance finding.

Among women who stopped smoking in early pregnancy, we observed risks of cryptorchidism similar to women smoking one to nine cigarettes during pregnancy, which may reflect the importance of the early prenatal exposure to tobacco smoking, where the fetus is more vulnerable. On the other hand, it could also indicate that these women actually were heavy smokers before pregnancy and share characteristics with smokers. In a subanalysis, we found no association between paternal smoking and cryptorchidism, but the association was strengthened when both parents smoked compared to maternal smoking alone. This could indicate that the sons were exposed to more passive smoking. It could also suggest that these women smoke to a larger extent and exposed the fetus for a longer period or more extensively than those women with a nonsmoking partner. Smoking is thought to induce hypoxia in the fetus caused by the vasoconstrictive effects of nicotine ${ }^{55}$ but contains thousands of other potentially toxic chemicals ${ }^{56}$ and is also associated with deficient or altered androgen signaling. ${ }^{57}$ Although the majority of existing literature does not support an association between smoking and cryptorchidism, ${ }^{8,9,12-14,17,19,23-25,27-31,34,35}$ our results are consistent with five previous studies, ${ }^{7,11,22,26}$ including those of a large Danish pregnancy cohort study by Jensen et $\mathrm{al}^{22}$ that also found a higher risk among sons exposed to $>10$ cigarettes/day.

Alcohol consumption during pregnancy is suspected to modify sex hormone levels in utero, which are essential for the descent of the testes. ${ }^{58}$ However, our results point toward a lower occurrence of cryptorchidism among sons of mothers who reported binge drinking during pregnancy. A majority of previous studies reported no association between weekly alcohol intake and cryptorchidism. ${ }^{9,11,12,17,19,21,25,26,28,29,32,35}$ A few studies have suggested a higher risk among binge drinkers $^{21,32}$ and yet others have observed a dose-responselike relationship with weekly alcohol consumption during pregnancy. ${ }^{13,15}$ A meta-analysis by Zhang et $\mathrm{al}^{33}$ indicated a lower risk of cryptorchidism in sons of pregnant women with low-to-moderate alcohol intake, whereas more than five drinks per week was associated with a higher risk. Our findings for binge drinking could be due to chance, selection bias, information bias or uncontrolled confounding, which is likely, as women binge drinking before versus after recognition of pregnancy have previously been shown to differ on other maternal characteristics in DNBC. ${ }^{59}$ Separating the two cohorts showed that the HR between binge drinking and cryptorchidism was only $<1$ in $\mathrm{DNBC}$, indicating that the women in this cohort may be healthier. ${ }^{60}$

Maternal overweight and obesity during pregnancy are associated with aberrant glycemic control and a less healthy nutritional status of the pregnant women. ${ }^{61}$ It has previously been associated with other congenital anomalies. ${ }^{62}$ In case of cryptorchidism, results have been mixed with some showing an association, whereas others not. ${ }^{6,9,10,12,14,16,18,23-26,31,33,34,63} \mathrm{~A}$ recent register-based Swedish study by Arendt et al, ${ }^{63}$ including $1,055,705$ boys, found results similar to ours regarding cryptorchidism and obesity.

High caffeine consumption during pregnancy has previously been associated with pregnancy complications ${ }^{64}$ and fetal death. ${ }^{65}$ Maternal caffeine intake could result in disturbed development of the fetus because of uteroplacental vasoconstriction due to rise in maternal serum catecholamine levels and reduced blood flow to the placenta ${ }^{66}$ However, we found no indication to support an effect of caffeine on the risk of cryptorchidism. Only three case-control studies with a small sample size have explored the relation between maternal caffeine levels and cryptorchidism with different results. ., $^{9,28}$

The discrepancies in previous studies on maternal lifestyle and cryptorchidism in boys could be caused by differences in ascertainment of cryptorchidism. We have classified boys with cryptorchidism using both registration 
of diagnosis and corrective surgery from the Danish National Patient Registry, which has been shown to have a high positive predictive value. ${ }^{48}$

The present study provides sufficient power to investigate our hypotheses, although some exposures only had few highly exposed. In addition to the high number of participants, another major strength of this study was the detailed prospectively collected information on lifestyle factors and potential confounding factors from the two Danish birth cohorts. Thus, we were able to adjust for several potential confounders, yet residual confounding or confounding from unknown factors cannot be ruled out. For instance, we did not have information about diet and nutrition, and nutritional deficiencies may well be a potential confounder. We were to some extent limited by lack of information on coffee aversion and nausea in $\mathrm{ABC}$, and therefore, we restricted a subanalysis to DNBC that holds information on nausea. These analyses gave results comparable to our main results.

In both the $\mathrm{DNBC}$ and the $\mathrm{ABC}$, the participation rate was $\sim 60 \%$ and $80 \%$, and we used the Danish health care registers with negligible loss to follow-up. Selection bias due to nonparticipation at inclusion in both cohorts cannot be rejected but is probably not a major problem because of the early inclusion prior to the end point registration of genital anomalies or other pregnancy outcomes. Yet, participation may be associated with both the exposure and potential factors directly linked to cryptorchidism, such as time to pregnancy or prior congenital malformations. We assume that this will only be of minor importance. ${ }^{60}$ Furthermore, our imputed model yielded results similar to the complete case analysis. We only included live-born singleton boys, which could be a potential selection problem often referred to as live-birth bias. ${ }^{67}$ The lifestyle factors are all associated with a higher risk of fetal death, ${ }^{65,68-70}$ and among fetal deaths, the occurrence of congenital abnormalities is high. ${ }^{71}$ If the most highly exposed fetuses died before birth, it could theoretically have biased our results toward the null. However, cryptorchidism is a milder congenital malformation unrecognized before birth; we therefore consider this to be a minor issue.

We expect some degree of misclassification and recall bias; however, we consider it likely to be mostly non-differential, as information on lifestyle factors was collected in early pregnancy by telephone interviews in DNBC and self-administered questionnaires in $\mathrm{ABC}$.

A large Norwegian cohort study comparing self-reported smoking status and plasma cotinine concentrations revealed that self-reported smoking is a valid marker for tobacco exposure in utero. ${ }^{72}$ Further, to evaluate the validity of our tobacco smoking information, we corroborated the wellknown reduction in birth weight with increasing levels of tobacco smoking during pregnancy. ${ }^{53}$ Boys exposed to 15 or more cigarettes per day on average had 292 grams (95\% CI: -318 ; -266) lower birth weight than sons of non-smokers. Information on maternal alcohol intake may to some extent be underreported ${ }^{73,74}$ due to the widespread consensus that alcohol consumption during pregnancy may damage the fetus. However, interviews and questionnaires have been shown to be reliable methods to collect information on the overall distribution of alcohol consumption in pregnant Danish women. ${ }^{73}$ In addition, body weight tends to be underreported, and there might also be some degree of misclassification in our data. ${ }^{75}$ We consider information about caffeine consumption not to be underreported, mainly because intake of coffee, tea and cola during pregnancy is widely accepted in Denmark. In addition, we were able to include caffeine exposure not only from tea and coffee consumption but also from intake of cola. Caffeine content depends highly on types of coffee, tea and cola and brewing methods. Unfortunately, this type of data was unavailable.

This study benefits from the use of two large birth cohorts, and by virtue of the study strengths and limitations, we believe that these findings are rather valid and may apply to other populations. Future studies could, if possible, look at siblings with different in utero exposure to limit the unmeasured time stable confounding.

\section{Conclusion}

In this large population-based cohort study, maternal tobacco smoking during pregnancy and maternal prepregnancy obesity were associated with an increased occurrence of cryptorchidism in sons, while alcohol or caffeine intake was not.

\section{Acknowledgments}

The DNBC was established with a significant grant from the Danish National Research Foundation. Additional support was obtained from the Danish Regional Committees, the Pharmacy Foundation, the Egmont Foundation, the March of Dimes Birth Defects Foundation, the Health Foundation and other minor grants. The DNBC Biobank has been supported by the Novo Nordisk Foundation and the Lundbeck Foundation. Follow-up of mothers and children has been supported by the Danish Medical Research Council (SSVF 0646, 271-08-0839/06-066023, O602-01042B, 060202738B), the Lundbeck Foundation (195/04, R100-A9193), the Innovation Fund Denmark 0603-00294B (09-067124), 
the Nordea Foundation (02-2013-2014), Aarhus Ideas (AU R9-A959-13-S804), the University of Copenhagen Strategic Grant (IFSV 2012), and the Danish Council for Independent Research (DFF - 4183-00594 and DFF - 4183-00152). The ABC was supported by the Danish Research Council; the Danish Agency for Science, Technology and Innovation; the Aase and Einar Danielsen's Fond and the Aarhus University Research Foundation. The Danish Council for Independent Research supported the study by providing a scholarship (DFF - 6110-00360) to Camilla Kjersgaard.

\section{Disclosure}

The authors report no conflicts of interest in this work.

\section{References}

1. Cortes D, Kjellberg EM, Breddam M, Thorup J. The true incidence of cryptorchidism in Denmark. J Urol. 2008;179(1):314-318.

2. Komarowska MD, Hermanowicz A, Debek W. Putting the pieces together: cryptorchidism - do we know everything? J Pediatr Endocrinol Metab. 2015;28(11-12):1247-1256.

3. Jensen MS, Wilcox AJ, Olsen J, et al. Cryptorchidism and hypospadias in a cohort of 934,538 Danish boys: the role of birth weight, gestational age, body dimensions, and fetal growth. Am J Epidemiol. 2012;175(9):917-925.

4. Jensen MS, Toft G, Thulstrup AM, et al. Cryptorchidism concordance in monozygotic and dizygotic twin brothers, full brothers, and halfbrothers. Fertil Steril. 2010;93(1):124-129.

5. Klonisch T, Fowler PA, Hombach-Klonisch S. Molecular and genetic regulation of testis descent and external genitalia development. Dev Biol. 2004;270(1):1-18.

6. Adams SV, Hastert TA, Huang Y, Starr JR. No association between maternal pre-pregnancy obesity and risk of hypospadias or cryptorchidism in male newborns. Birth Defects Res A Clin Mol Teratol. 2011;91(4): 241-248.

7. Akre O, Lipworth L, Cnattingius S, Sparen P, Ekbom A. Risk factor patterns for cryptorchidism and hypospadias. Epidemiology. 1999;10(4):364-369.

8. Beard CM, Melton LJ 3rd, O'Fallon WM, Noller KL, Benson RC. Cryptorchism and maternal estrogen exposure. Am J Epidemiol. 1984;120(5):707-716.

9. Berkowitz GS, Lapinski RH. Risk factors for cryptorchidism: a nested case-control study. Paediatr Perinat Epidemiol. 1996;10(1):39-51.

10. Berkowitz GS, Lapinski RH, Godbold JH, Dolgin SE, Holzman IR. Maternal and neonatal risk factors for cryptorchidism. Epidemiology. 1995;6(2):127-131.

11. Biggs ML, Baer A, Critchlow CW. Maternal, delivery, and perinatal characteristics associated with cryptorchidism: a population-based case-control study among births in Washington State. Epidemiology. 2002;13(2):197-204.

12. Brouwers MM, de Bruijne LM, de Gier RP, Zielhuis GA, Feitz WF, Roeleveld N. Risk factors for undescended testis. J Pediatr Urol. 2012;8(1):59-66.

13. Carbone P, Giordano F, Nori F, et al. The possible role of endocrine disrupting chemicals in the aetiology of cryptorchidism and hypospadias: a population-based case-control study in rural Sicily. Int J Androl. 2007;30(1):3-13.

14. Damgaard IN, Jensen TK; Nordic Cryptorchidism Study Group, et al. Risk factors for congenital cryptorchidism in a prospective birth cohort study. PLoS One. 2008;3(8):e3051.

15. Damgaard IN, Jensen TK, Petersen JH, Skakkebaek NE, Toppari J, Main KM. Cryptorchidism and maternal alcohol consumption during pregnancy. Environ Health Perspect. 2007;115(2):272-277.
16. Depue RH. Maternal and gestational factors affecting the risk of cryptorchidism and inguinal hernia. Int J Epidemiol. 1984;13(3):311-318.

17. Davies TW, Williams DR, Whitaker RH. Risk factors for undescended testis. Int J Epidemiol. 1986;15(2):197-201.

18. Fernandez MF, Olmos B, Granada A, et al. Human exposure to endocrine-disrupting chemicals and prenatal risk factors for cryptorchidism and hypospadias: a nested case-control study. Environ Health Perspect. 2007;115(suppl 1):8-14

19. Gaspari L, Paris F, Jandel C, et al. Prenatal environmental risk factors for genital malformations in a population of 1442 French male newborns: a nested case-control study. Hum Reprod. 2011;26(11):3155-3162.

20. Giordano F, Carbone P, Nori F, Mantovani A, Taruscio D, Figà-Talamanca I. Maternal diet and the risk of hypospadias and cryptorchidism in the offspring. Paediatr Perinat Epidemiol. 2008;22(3):249-260.

21. Jensen MS, Bonde JP, Olsen J. Prenatal alcohol exposure and cryptorchidism. Acta Paediatr. 2007;96(11):1681-1685.

22. Jensen MS, Toft G, Thulstrup AM, Bonde JP, Olsen J. Cryptorchidism according to maternal gestational smoking. Epidemiology. 2007;18(2):220-225.

23. Jones ME, Swerdlow AJ, Griffith M, Goldacre MJ. Prenatal risk factors for cryptorchidism: a record linkage study. Paediatr Perinat Epidemiol. 1998;12(4):383-396.

24. Kurahashi N, Kasai S, Shibata T, et al. Parental and neonatal risk factors for cryptorchidism. Med Sci Monit. 2005;11(6):CR274-CR283.

25. Mori M, Davies TW, Tsukamoto T, Kumamoto Y, Fukuda K. Maternal and other factors of cryptorchidism - a case-control study in Japan. Kurume Med J. 1992;39(2):53-60.

26. McBride ML, Van den Steen N, Lamb CW, Gallagher RP. Maternal and gestational factors in cryptorchidism. Int $J$ Epidemiol. 1991;20(4):964-970.

27. McGlynn KA, Graubard BI, Klebanoff MA, Longnecker MP. Risk factors for cryptorchism among populations at differing risks of testicular cancer. Int J Epidemiol. 2006;35(3):787-795.

28. Mongraw-Chaffin ML, Cohn BA, Cohen RD, Christianson RE. Maternal smoking, alcohol consumption, and caffeine consumption during pregnancy in relation to a son's risk of persistent cryptorchidism: a prospective study in the Child Health and Development Studies cohort, 1959-1967. Am J Epidemiol. 2008;167(3):257-261.

29. Møller H, Skakkebæk NE. Testicular cancer and cryptorchidism in relation to prenatal factors: case-control studies in Denmark. Cancer Causes Control. 1997;8(6):904-912.

30. Pierik FH, Burdorf A, Deddens JA, Juttmann RE, Weber RF. Maternal and paternal risk factors for cryptorchidism and hypospadias: a case-control study in newborn boys. Environ Health Perspect. 2004;112(15):1570-1576.

31. Preiksa RT, Zilaitiene B, Matulevicius V, et al. Higher than expected prevalence of congenital cryptorchidism in Lithuania: a study of 1204 boys at birth and 1 year follow-up. Hum Reprod. 2005;20(7):1928-1932.

32. Strandberg-Larsen K, Jensen MS, Ramlau-Hansen CH, Gronbaek M, Olsen J. Alcohol binge drinking during pregnancy and cryptorchidism. Hum Reprod. 2009;24(12):3211-3219.

33. Zhang L, Wang XH, Zheng XM, et al. Maternal gestational smoking, diabetes, alcohol drinking, pre-pregnancy obesity and the risk of cryptorchidism: a systematic review and meta-analysis of observational studies. PLoS One. 2015;10(3):e0119006.

34. Virtanen HE, Tapanainen AE, Kaleva MM, et al. Mild gestational diabetes as a risk factor for congenital cryptorchidism. J Clin Endocrinol Metab. 2006;91(12):4862-4865.

35. Wagner-Mahler K, Kurzenne JY, Delattre I, et al. Prospective study on the prevalence and associated risk factors of cryptorchidism in 6246 newborn boys from Nice area, France. Int J Androl. 2011;34(5 pt 2):e499-e510.

36. Olsen J, Melbye M, Olsen SF, et al. The Danish National Birth Cohort - its background, structure and aim. Scand J Public Health. 2001;29(4):300-307.

37. Olsen J. Nine months that last a lifetime. Experience from the Danish National Birth Cohort and lessons learned. Int J Hyg Environ Health. 2012;215(2):142-144. 
38. Kettner LO, Ramlau-Hansen CH, Kesmodel US, Bay B, Matthiesen NB, Henriksen TB. Parental infertility, fertility treatment, and childhood epilepsy: a population-based cohort study. Paediatr Perinat Epidemiol. 2016;30(5):488-495.

39. Henriksen TB, Baird DD, Olsen J, Hedegaard M, Secher NJ, Wilcox AJ. Time to pregnancy and preterm delivery. Obstet Gynecol. 1997;89(4):594-599.

40. Pedersen CB. The Danish civil registration system. Scand J Public Health. 2011;39(7 suppl):22-25.

41. Knudsen LB, Olsen J. The Danish medical birth registry. Dan Med Bull. 1998;45(3):320-323.

42. Lynge E, Sandegaard JL, Rebolj M. The Danish national patient register. Scand J Public Health. 2011;39(7 suppl):30-33.

43. Petersson F, Baadsgaard M, Thygesen LC. Danish registers on personal labour market affiliation. Scand J Public Health. 2011;39(7 suppl):95-98.

44. euro.WHO.int. [homepage on the Internet]. Nutrition - Body mass index - BMI. Available from: http://www.euro.who.int/en/health-topics/ disease-prevention/nutrition/a-healthy-lifestyle/body-mass-index-bmi. Accessed January 01, 2018.

45. Bunker ML, McWilliams M. Caffeine content of common beverages. J Am Diet Assoc. 1979;74(1):28-32.

46. Bracken MB, Triche E, Grosso L, Hellenbrand K, Belanger K, Leaderer BP. Heterogeneity in assessing self-reports of caffeine exposure: implications for studies of health effects. Epidemiology. 2002;13(2): $165-171$.

47. Hernan MA, Hernandez-Diaz S, Werler MM, Mitchell AA. Causal knowledge as a prerequisite for confounding evaluation: an application to birth defects epidemiology. Am J Epidemiol. 2002;155(2): 176-184.

48. Jensen MS, Snerum TM, Olsen LH, et al. Accuracy of cryptorchidism diagnoses and corrective surgical treatment registration in the Danish National Patient Registry. J Urol. 2012;188(4):1324-1329.

49. Sterne JA, White IR, Carlin JB, et al. Multiple imputation for missing data in epidemiological and clinical research: potential and pitfalls. BMJ. 2009;338:b2393.

50. Bhaskaran K, Smeeth L. What is the difference between missing completely at random and missing at random? Int $J$ Epidemiol. 2014;43(4):1336-1339.

51. White IR, Royston P, Wood AM. Multiple imputation using chained equations: issues and guidance for practice. Stat Med. 2011;30(4):377-399.

52. Jensen MS, Olsen LH, Thulstrup AM, Bonde JP, Olsen J, Henriksen TB. Age at cryptorchidism diagnosis and orchiopexy in Denmark: a population based study of 508,964 boys born from 1995 to 2009 . $J$ Urol. 2011;186(4 Suppl):1595-1600.

53. England LJ, Kendrick JS, Gargiullo PM, Zahniser SC, Hannon WH. Measures of maternal tobacco exposure and infant birth weight at term. Am J Epidemiol. 2001;153(10):954-960.

54. Stein Z, Susser M. Miscarriage, caffeine, and the epiphenomena of pregnancy: the causal model. Epidemiology. 1991;2(3):163-167.

55. Mochizuki M, Maruo T, Masuko K, Ohtsu T. Effects of smoking on fetoplacental-maternal system during pregnancy. Am J Obstet Gynecol. 1984;149(4):413-420.

56. Talhout R, Schulz T, Florek E, van Benthem J, Wester P, Opperhuizen A. Hazardous compounds in tobacco smoke. Int J Environ Res Public Health. 2011;8(2):613-628.

57. Fowler PA, Bhattacharya S, Flannigan S, Drake AJ, O'Shaughnessy PJ. Maternal cigarette smoking and effects on androgen action in male offspring: unexpected effects on second-trimester anogenital distance. J Clin Endocrinol Metab. 2011;96(9):E1502-E1506.
58. Stevens RG, Cohen RD, Terry MB, Lasley BL, Siiteri P, Cohn BA. Alcohol consumption and serum hormone levels during pregnancy. Alcohol. 2005;36(1):47-53.

59. Strandberg-Larsen K, Rod Nielsen N, Nybo Andersen AM, Olsen J, Gronbaek M. Characteristics of women who binge drink before and after they become aware of their pregnancy. Eur J Epidemiol. 2008;23(8):565-572.

60. Nohr EA, Frydenberg M, Henriksen TB, Olsen J. Does low participation in cohort studies induce bias? Epidemiology. 2006;17(4):413-418.

61. Carmichael SL, Rasmussen SA, Shaw GM. Prepregnancy obesity: a complex risk factor for selected birth defects. Birth Defects Res A Clin Mol Teratol. 2010;88(10):804-810.

62. Stothard KJ, Tennant PW, Bell R, Rankin J. Maternal overweight and obesity and the risk of congenital anomalies: a systematic review and meta-analysis. JAMA. 2009;301(6):636-650.

63. Arendt LH, Ramlau-Hansen CH, Lindhard MS, et al. Maternal overweight and obesity and genital anomalies in male offspring: a population-based Swedish cohort study. Paediatr Perinat Epidemiol. 2017;31(4):317-327.

64. Fortier I, Marcoux S, Beaulac-Baillargeon L. Relation of caffeine intake during pregnancy to intrauterine growth retardation and preterm birth. Am J Epidemiol. 1993;137(9):931-940.

65. Bech BH, Nohr EA, Vaeth M, Henriksen TB, Olsen J. Coffee and fetal death: a cohort study with prospective data. Am JEpidemiol. 2005;162(10): 983-990.

66. Kirkinen P, Jouppila P, Koivula A, Vuori J, Puukka M. The effect of caffeine on placental and fetal blood flow in human pregnancy. Am J Obstet Gynecol. 1983;147(8):939-942.

67. Liew Z, Olsen J, Cui X, Ritz B, Arah OA. Bias from conditioning on live birth in pregnancy cohorts: an illustration based on neurodevelopment in children after prenatal exposure to organic pollutants. Int J Epidemiol. 2015;44(1):345-354.

68. Andersen AM, Andersen PK, Olsen J, Gronbaek M, Strandberg-Larsen $\mathrm{K}$. Moderate alcohol intake during pregnancy and risk of fetal death. Int J Epidemiol. 2012;41(2):405-413.

69. Wu T, Buck G, Mendola P. Maternal cigarette smoking, regular use of multivitamin/mineral supplements, and risk of fetal death: the 1988 National Maternal and Infant Health Survey. Am J Epidemiol. 1998;148(2):215-221.

70. Aune D, Saugstad OD, Henriksen T, Tonstad S. Maternal body mass index and the risk of fetal death, stillbirth, and infant death: a systematic review and meta-analysis. JAMA. 2014;311(15):1536-1546.

71. Eurocat-network.eu. [homepage on the Internet]. EUROCAT: European Surveillance of Congenital Anomalies. 2017. Available from: http:// www.eurocat-network.eu/accessprevalencedata/prevalencetables. Accessed April 07, 2017.

72. Kvalvik LG, Nilsen RM, Skjærven R, et al. Self-reported smoking status and plasma cotinine concentrations among pregnant women in the Norwegian Mother and Child Cohort study. Pediatr Res. 2012;72(1):101-107.

73. Kesmodel U, Olsen SF. Self reported alcohol intake in pregnancy: comparison between four methods. J Epidemiol Community Health. 2001;55(10):738-745.

74. Alvik A, Haldorsen T, Groholt B, Lindemann R. Alcohol consumption before and during pregnancy comparing concurrent and retrospective reports. Alcohol Clin Exp Res. 2006;30(3):510-515.

75. Fattah C, Farah N, O’Toole F, Barry S, Stuart B, Turner MJ. Body mass index (BMI) in women booking for antenatal care: comparison between selfreported and digital measurements. Eur J Obstet Gynecol Reprod Biol. 2009;144(1):32-34.

76. Stein Z, Susser M. Miscarriage, caffeine, and the epiphenomena of pregnancy: the causal model. Epidemiology. 1991;2(3):163-167. 


\section{Supplementary materials}

Table SI HRs for cryptorchidism according to maternal smoking, weekly alcohol intake, binge drinking, prepregnancy BMI and caffeine intake during pregnancy among 85,923 singleton live-born boys, Denmark, 1989-2012 (Complete case)

\begin{tabular}{|c|c|c|c|c|c|c|c|c|c|}
\hline \multirow[t]{2}{*}{ Characteristic } & \multirow{2}{*}{$\begin{array}{l}\text { Distribution of } \\
\text { participants, \% }\end{array}$} & \multicolumn{4}{|c|}{ Cryptorchidism - diagnosis } & \multicolumn{4}{|c|}{ Cryptorchidism - surgery } \\
\hline & & Cases, \% & Crude HR & aHR & $95 \% \mathrm{Cl}$ & Cases, \% & Crude HR & aHR & $95 \% \mathrm{Cl}$ \\
\hline \multicolumn{10}{|c|}{ Smoking (cigarettes/day) } \\
\hline Complete observations $^{\mathrm{a}}$ & 84.2 & & & & & & & & \\
\hline Nonsmoker & 73.8 & 2.0 & 1.00 & 1.00 & Reference & 1.2 & 1.00 & 1.00 & Reference \\
\hline Stopped smokers & 9.7 & 2.5 & 1.22 & 1.20 & $(I .02-I .4 I)$ & $\mathrm{I} .4$ & 1.19 & 1.19 & $(0.97-1.47)$ \\
\hline $1-9$ & 8.6 & 2.4 & 1.10 & 1.13 & $(0.95-1.34)$ & 1.5 & 1.17 & 1.21 & $(0.97-1.52)$ \\
\hline $10-14$ & 4.7 & 2.7 & 1.21 & 1.26 & $(1.01-1.57)$ & 1.8 & 1.40 & 1.58 & $(1.21-2.06)$ \\
\hline$\geq 15$ & 2.9 & 2.6 & 1.18 & 1.00 & $(0.73-1.36)$ & 1.5 & 1.13 & 0.90 & $(0.59-1.39)$ \\
\hline Wald test & & & & & $p=0.06$ & & & & $p=0.01$ \\
\hline \multicolumn{10}{|l|}{ Alcohol (drinks/week) ${ }^{b}$} \\
\hline Complete observations ${ }^{\mathrm{b}}$ & 84.2 & & & & & & & & \\
\hline None to $<1$ & 70.8 & 2.2 & 1.00 & 1.00 & Reference & 1.3 & 1.00 & 1.00 & Reference \\
\hline $\mathrm{I}-2$ & 19.7 & 2.2 & 0.88 & 0.92 & $(0.8 I-1.04)$ & 1.2 & 0.84 & 0.88 & $(0.74-1.04)$ \\
\hline $3-4$ & 3.9 & 2.1 & 0.93 & 0.81 & $(0.6 \mathrm{I}-1.07)$ & 1.3 & 0.97 & 0.93 & $(0.66-1.30)$ \\
\hline$\geq 5$ & 1.6 & 1.4 & 0.71 & 0.73 & $(0.45-1.17)$ & 1.1 & 0.90 & 0.83 & $(0.47-1.47)$ \\
\hline Wald test & & & & & $p=0.17$ & & & & $p=0.47$ \\
\hline \multicolumn{10}{|c|}{ Binge drinking episodes(times) ${ }^{b}$} \\
\hline Complete observations ${ }^{\mathrm{b}}$ & 82.7 & & & & & & & & \\
\hline None & 61.6 & 2.3 & 1.00 & 1.00 & Reference & 1.4 & 1.00 & 1.00 & Reference \\
\hline I & 16.6 & 1.8 & 0.85 & 0.83 & $(0.7 I-0.98)$ & I.I & 0.86 & 0.79 & $(0.64-0.96)$ \\
\hline 2 & 6.3 & 1.8 & 0.85 & 0.79 & $(0.62-1.01)$ & 1.0 & 0.80 & 0.67 & $(0.49-0.93)$ \\
\hline$\geq 3$ & 3.9 & 2.2 & 1.03 & 0.92 & $(0.69-1.22)$ & $\mathrm{I} .4$ & 1.14 & 0.94 & $(0.66-1.33)$ \\
\hline Wald test & & & & & $p=0.05$ & & & & $p=0.02$ \\
\hline \multicolumn{10}{|c|}{ Prepregnancy BMI $\left(\mathrm{kg} / \mathrm{m}^{2}\right)^{\mathrm{c}}$} \\
\hline Complete observations ${ }^{c}$ & 86.5 & & & & & & & & \\
\hline$<18.5$ & 4.9 & 2.3 & 1.12 & 1.08 & $(0.86-1.36)$ & 1.3 & 1.03 & 0.98 & $(0.73-1.33)$ \\
\hline $18.5-24.9$ & 67.3 & 2.0 & 1.00 & 1.00 & Reference & 1.2 & 1.00 & 1.00 & Reference \\
\hline $25-29.9$ & 16.8 & 2.6 & 1.33 & 1.33 & $(I .17-I .5 I)$ & $\mathrm{I} .4$ & 1.19 & 1.18 & $(1.00-1.40)$ \\
\hline$\geq 30$ & 6.8 & 2.6 & 1.30 & 1.26 & $(1.05-1.52)$ & 1.6 & 1.34 & 1.30 & $(1.02-1.64)$ \\
\hline Wald test & & & & & $p=0.00$ & & & & $p=0.06$ \\
\hline \multicolumn{10}{|l|}{ Caffeine (mg/day) $)^{d}$} \\
\hline Complete observations $^{d}$ & 84.2 & & & & & & & & \\
\hline None & 9.4 & 1.9 & 0.98 & 0.96 & $(0.80-1.16)$ & 1.0 & 0.98 & 0.95 & $(0.75-1.2 I)$ \\
\hline $\mathrm{I}-300$ & 64.4 & 2.1 & 1.00 & 1.00 & Reference & 1.3 & 1.00 & 1.00 & Reference \\
\hline $400-600$ & 14.3 & 2.4 & 1.05 & 1.08 & $(0.93-1.24)$ & $\mathrm{I} .4$ & 1.01 & 1.03 & $(0.85-1.24)$ \\
\hline$>600$ & 5.5 & 2.5 & 1.06 & 1.11 & $(0.90-1.37)$ & 1.5 & 1.04 & 1.11 & $(0.85-1.45)$ \\
\hline Wald test & & & & & $p=0.59$ & & & & $p=0.85$ \\
\hline
\end{tabular}

Notes: 'Adjusted for maternal years of education, maternal age at delivery, parity, calendar year, cohort, mothers' caffeine intake and alcohol intake, maternal prepregnancy $\mathrm{BMI}$ and time to index pregnancy. 'ंAdjusted for maternal years of education, maternal age at delivery, parity, calendar year, cohort, mothers' caffeine intake and smoking, maternal prepregnancy BMI and time to index pregnancy. 'Adjusted for maternal years of education, maternal age at delivery, parity, calendar year, cohort, mothers' caffeine intake and alcohol intake and maternal smoking during pregnancy. 'Adjusted for maternal years of education, maternal age at delivery, parity, calendar year, cohort, mothers' alcohol intake and smoking, maternal prepregnancy BMI and time to index pregnancy.

Abbreviations: HR, hazard ratio; BMI, body mass index; aHR, adjusted hazard ratio. 
Table S2 HRs for cryptorchidism according to maternal smoking, weekly alcohol intake, binge drinking, prepregnancy BMI and caffeine intake in ABC and the DNBC among 85,923 singleton live-born boys, Denmark, 1989-2012 (Complete case stratified by birth cohort)

\begin{tabular}{|c|c|c|c|c|c|c|c|c|c|c|}
\hline \multirow[t]{3}{*}{ Characteristic } & \multicolumn{5}{|c|}{ DNBC $(n=46,165)$} & \multicolumn{5}{|c|}{$A B C(n=39,758)$} \\
\hline & \multicolumn{2}{|c|}{$\begin{array}{l}\text { Distribution of } \\
\text { participants }\end{array}$} & \multirow[t]{2}{*}{$\begin{array}{l}\text { Crude } \\
\text { HR }\end{array}$} & \multirow[t]{2}{*}{ aHR } & \multirow[t]{2}{*}{$95 \% \mathrm{Cl}$} & \multicolumn{2}{|c|}{$\begin{array}{l}\text { Distribution of } \\
\text { participants }\end{array}$} & \multirow[t]{2}{*}{$\begin{array}{l}\text { Crude } \\
\text { HR }\end{array}$} & \multirow[t]{2}{*}{ aHR } & \multirow[t]{2}{*}{$95 \% \mathrm{Cl}$} \\
\hline & Total, \% & Cases, \% & & & & Total, \% & Cases, \% & & & \\
\hline \multicolumn{11}{|c|}{ Smoking (cigarettes/day) ${ }^{a}$} \\
\hline Nonsmoker & 74.4 & 1.3 & 1.00 & 1.00 & Reference & 73.1 & I.I & 1.00 & 1.00 & Reference \\
\hline Stopped smokers & 9.1 & 1.6 & 1.29 & 1.26 & $(0.97-1.63)$ & 10.4 & 1.3 & 1.07 & 1.09 & $(0.77-1.54)$ \\
\hline $1-9$ & 9.0 & 1.5 & 1.15 & 1.16 & $(0.88-1.54)$ & 8.2 & 1.6 & 1.20 & 1.29 & $(0.89-1.86)$ \\
\hline $10-14$ & 4.6 & 2.1 & 1.64 & 1.66 & $(1.19-2.32)$ & 4.9 & 1.6 & 1.14 & 1.43 & $(0.91-2.25)$ \\
\hline \multirow{2}{*}{$\geq 15$} & 2.9 & 1.5 & 1.18 & 0.99 & $(0.59-1.65)$ & 3.0 & 1.4 & 1.07 & 0.75 & $(0.34-1.66)$ \\
\hline & 0.1 & & & & & 0.5 & & & & \\
\hline \multicolumn{11}{|c|}{ Alcohol (drinks/week) ${ }^{b}$} \\
\hline None to $<1$ & 70.9 & $\mathrm{I} .4$ & 1.00 & 1.00 & Reference & 70.6 & 1.2 & 1.00 & 1.00 & Reference \\
\hline $\mathrm{I}-2$ & 24.4 & 1.2 & 0.86 & 0.88 & $(0.72-1.07)$ & 14.1 & I.I & 0.79 & 0.90 & $(0.65-1.24)$ \\
\hline $3-4$ & 3.6 & 1.3 & 0.94 & 0.88 & $(0.55-1.40)$ & 4.4 & 1.3 & 1.01 & 1.01 & $(0.6 \mathrm{I}-1.66)$ \\
\hline \multirow[t]{2}{*}{$\geq 5$} & 1.0 & 1.3 & 0.88 & 0.96 & $(0.43-2.15)$ & 2.3 & 1.0 & 0.91 & 0.73 & $(0.32-1.66)$ \\
\hline & 0.1 & & & & & 8.6 & & & & \\
\hline \multicolumn{11}{|c|}{$\begin{array}{l}\text { Binge drinking episodes } \\
\text { (times) }^{\mathrm{b}}\end{array}$} \\
\hline None & 74.8 & $\mathrm{I} .4$ & 1.00 & 1.00 & Reference & 35.1 & 1.2 & 1.00 & 1.00 & Reference \\
\hline 1 & 16.0 & I.I & 0.78 & 0.74 & $(0.58-0.94)$ & 17.9 & 1.0 & 1.06 & 0.98 & $(0.66-1.44)$ \\
\hline 2 & 5.6 & 1.0 & 0.67 & 0.57 & $(0.37-0.88)$ & 7.8 & I.I & 1.07 & 0.93 & $(0.55-1.55)$ \\
\hline \multirow[t]{2}{*}{$\geq 3$} & 3.5 & 1.5 & 1.04 & 0.93 & $(0.61-1.42)$ & 4.8 & 1.4 & 1.34 & 1.02 & $(0.54-1.92)$ \\
\hline & 0.2 & & & & & 34.4 & & & & \\
\hline \multicolumn{11}{|c|}{ Prepregnancy BMI $\left(\mathrm{kg} / \mathrm{m}^{2}\right)^{\mathrm{c}}$} \\
\hline$<18.5$ & 4.3 & 1.5 & 1.12 & 1.08 & $(0.74-1.57)$ & 5.5 & I.I & 0.94 & 0.85 & $(0.5 I-I .4 I)$ \\
\hline $18.5-24.9$ & 64.2 & 1.3 & 1.00 & 1.00 & Reference & 70.9 & 1.1 & 1.00 & 1.00 & Reference \\
\hline $25-29.9$ & 18.4 & 1.5 & 1.11 & 1.10 & $(0.90-1.36)$ & 14.9 & 1.4 & 1.32 & 1.36 & $(1.03-1.81)$ \\
\hline \multirow[t]{2}{*}{$\geq 30$} & 7.7 & 1.6 & 1.21 & 1.21 & $(0.91-1.61)$ & 5.7 & 1.6 & 1.59 & 1.54 & $(1.01-2.34)$ \\
\hline & 5.3 & & & & & 2.9 & & & & \\
\hline \multicolumn{11}{|c|}{ Caffeine (mg/day) $)^{d}$} \\
\hline 0 & 6.6 & $\mathrm{I} .4$ & 1.01 & 1.03 & $(0.74-I .42)$ & 12.6 & 1.0 & 0.92 & 0.87 & $(0.6 I-I .24)$ \\
\hline $1-300$ & 70.0 & 1.3 & 1.00 & 1.00 & Reference & 57.9 & 1.2 & 1.00 & 1.00 & Reference \\
\hline $30 I-600$ & 16.1 & 1.5 & 1.08 & 1.07 & $(0.85-1.35)$ & 12.3 & 1.3 & 0.91 & 0.96 & $(0.69-1.33)$ \\
\hline \multirow[t]{2}{*}{$>600$} & 7.1 & 1.4 & 1.06 & 1.08 & (0.78-I.48) & 3.5 & 1.5 & 1.01 & 1.23 & $(0.75-2.03)$ \\
\hline & 0.1 & & & & & 13.6 & & & & \\
\hline
\end{tabular}

Notes: 'Adjusted for maternal years of education, maternal age at delivery, parity, calendar year, cohort, mothers' caffeine intake and alcohol intake, maternal prepregnancy

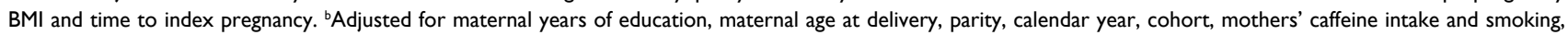
maternal prepregnancy BMI and time to index pregnancy. 'Adjusted for maternal years of education, maternal age at delivery, parity, calendar year, cohort, mothers' caffeine intake and alcohol intake and maternal smoking during pregnancy. 'Adjusted for maternal years of education, maternal age at delivery, parity, calendar year, cohort, mothers' alcohol intake and smoking, maternal prepregnancy $\mathrm{BMI}$ and time to index pregnancy.

Abbreviations: HR, hazard ratio; BMI, body mass index; ABC, Aarhus Birth Cohort; DNBC, Danish National Birth Cohort; aHR, adjusted hazard ratio.

\section{Publish your work in this journal}

Clinical Epidemiology is an international, peer-reviewed, open access, online journal focusing on disease and drug epidemiology, identification of risk factors and screening procedures to develop optimal preventative initiatives and programs. Specific topics include: diagnosis, prognosis, treatment, screening, prevention, risk factor modification,

Submit your manuscript here: https://www.dovepress.com/clinical-epidemiology-journa systematic reviews, risk and safety of medical interventions, epidemiology and biostatistical methods, and evaluation of guidelines, translational medicine, health policies and economic evaluations. The manuscript management system is completely online and includes a very quick and fair peer-review system, which is all easy to use. 